\title{
Application of F-WASPAS in the Ranking of Crops for Agro-Processing: The Case of Ikondo Ward in Njombe, Tanzania
}

\author{
Benito G Mng'ong'o ${ }^{1}$ and David Koloseni ${ }^{{ }^{*}}$ \\ ${ }^{I}$ Mkwawa University College of Education, University of Dar es Salaam, Tanzania \\ E-mail: bengapar2008@gmail.com \\ ${ }^{2}$ Department of Mathematics, University of Dar es Salaam, Tanzania \\ *Corresponding author,E-mail: dkdavykol@gmail.com; koloseni.david@udsm.ac.tz \\ Received 6 Oct 2021, Revised 17 Dec 2021, Accepted 27 Dec 2021, Published Dec 2021 \\ DOI: https://dx.doi.org/10.4314/tjs.v47i5.26
}

\begin{abstract}
The purpose of this work was to develop and apply a Fuzzy Weighted Aggregated Sum Product Assessment (F-WASPAS) method in ranking selected crops for agro-processing at Ikondo Ward in Njombe Region, Tanzania. The fuzzy technique for order preferences by similarity to ideal solution (TOPSIS) was applied in determining the fuzzy importance weights of criteria, while the fuzzy WASPAS successfully ranked the crops, and maize was ranked the highest.
\end{abstract}

Keywords: F-WASPAS, Linguistic variables, Fuzzy aggregation, Agro-processing, Decision making, Multi-Criteria Decision Making.

\section{Introduction}

The environment in which people live is usually full of issues that require selecting and/or prioritizing the best among the available or infinite number of alternatives or possible options. Thus ranking or/and optimising is essential, and in that case, decision making is required. Decision making can simply mean selecting or choosing the course of action or direction among possible alternatives. Decision-making is found in various fields (Setyawan et al. 2017), and is a complex process with multiple and usually conflicting criteria or objectives (Turskis et al. 2015). Each alternative or option to a certain extent may suit (or not suit) some criteria that influence selection as Sabaei et al. (2015) wrote, "Often none of the alternatives fit perfectly to achieve goals". The decision making process that involves many criteria is termed Multi-Criteria Decision Making (MCDM).

There are several Multi-Criteria Decision Making (MDCM) methods already proposed by previous researchers and others that may be developed (Chakraborty and Zavadskas 2014). When these methods are applied, it is common to find multiple and usually conflicting criteria in planning, and particularly in decision-making processes (Rodcha et al. 2019). MCDM methods give methodological as well as logical procedures that at the same time use preferences of decision-makers on criteria and alternatives in order to obtain the optimum alternative (Chakraborty and Zavadskas 2014). MCDM is a modelling and methodological tool to deal with complex decision making-problems (Rouyendegh and Erkan 2012). It is a Mathematical way of making a decision (Dhiman et al. 2019). The development of MCDM modelling as a discipline is closely related to advances in computer technology (Srisawat and Payakpate 2016). Singh and Malik (2014) provide areas where MCDM is applied, such as in education, management, manufacturing, transportation, planning, medical, agriculture, logistics, control systems and other fields of engineering where selection, ranking and alternatives evaluation 
is required. Singh and Malik (2014) also categorise MCDM into multi-attribute decision-making (MADM) that is also known as discrete MCDM (Puertas et al. 2020) and multi-objective decision-making (MODM). MODM is a continuous MCDM or multiobjective optimisation problems (MOOPs) (Puertas et al. 2020). MODM uses tools such as goal programming, multiple objective programming, and compromise solution methods, while tools like AHP and TOPSIS (classical or fuzzy) are for MADM. MADM involves selecting the best alternative from a pre-specified set of alternatives evaluated in terms of multiple criteria or attributes, while MODM requires obtaining the best alternative/alternatives that optimise the multiple objectives from an infinite number of alternatives or options.

The Weighted Aggregated Sum Product Assessment (WASPAS), one of the recently developed MCDM methods was originally developed by Zavadskas et al. in 2012 (Stojić et al. 2018). The WASPAS method permits evaluating and ranking the alternatives with higher order of reliability and consistency.

WASPAS method mainly makes use of two methods; the Weighted Sum Method (WSM) and the Weighted Product Method (WPM) (Petrović et al. 2019). WASPAS method is one of the most efficient decisionmaking methods applied in several areas like engineering and managerial fields (Keshavarz-Ghorabaee et al. 2020). WASPAS method has been extended for many decisionmaking problems under different fuzzy policies and Badalpur and Nurbakhsh (2019) commended WASPAS as a capable and more accurate method compared to other standalone WSM or WPM methods for ranking alternatives.

Several studies on different crops and plants employing WASPAS or F-WASPAS method have been presented. For example, WASPAS is used in different areas for solving MCDM problems; Chandrawati et al. (2020) used F-WASPAS (that employs fuzzy numbers) for path selection, KeshavarzGhorabaee et al. (2020) employed a new decision-making approach based on fermatean fuzzy sets and WASPAS for green construction supplier evaluation, Ighravwe and Oke (2017) applied a fuzzy greyweighted aggregate sum product assessment methodical approach for multi-criteria analysis of maintenance of performance systems, and Turskis et al. (2019) applied a fuzzy WASPAS-based approach to determine critical information infrastructure of EU sustainable development. To take care of uncertainities and vague information, Fuzzy WASPAS (F-WASPAS) was applied in several studies. For example, Chakraborty and Zavadskas (2014) applied, weighted aggregated sum product assessment (WASPAS) method tool in solving eight manufacturing decision-making problems, such as selection of cutting fluid, electroplating system, forging condition, arc welding process, industrial robots, milling conditions, machinability of materials, and electro-discharge micro-machining process parameters. The attempt observed that WASPAS method has the capability of accurately ranking the alternatives in all the considered selection problems as well as the effect of the parameter $\lambda$ on the ranking performance of WASPAS method.

In another development, Badalpur and Nurbakhsh (2019), used WASPAS method in evaluating the risks of a road construction project in Iran, in which the results showed inaccessibility/inappropriateness of barrow pits, loss of key manpower during the project life cycle; employing inexperienced subcontractors were of the most important risks among identified risks. Also, the authors suggested that WASPAS method is a suitable method with more accuracy among the MCDM techniques for evaluating risks in a real situation. A resilient-green supplier was chosen to build a supply chain environment with flexibility and greenness under interruption. Then, the integrated WASPAS and TOPSIS methods based on intuitionistic fuzzy numbers were applied to rank the alternatives to select the optimal resilientgreen supplier under the supply chain environment (Xiong et al. 2020).

WASPAS method too was applied to assess different portable hard disk drive alternatives, according to the customer liking 
concerning various attributes (Kumar et al. 2020). The ranking result showed that Western Digital hard disk drive came out to be the first choice brand among the top three models with equal and objective weights.

An Interval-Valued Intuitionistic Fuzzy WASPAS method is a constructive tool for decision-making in an uncertain environment (Mishra and Rani 2018). The method was applied to the uncertain decision-making problem of reservoir flood control management policy. The method computes the decisions on experts' alternatives weights and criteria weights based on interval-valued intuitionistic fuzzy information measures to achieve more representative weights.

Agro-processing includes processing, preservation and preparation of agricultural produce for intermediate and final consumption (Wilkinson and Rocha 2009), and Da Silva et al. (2009) added that agroprocessing is the conversion of raw food and/or agricultural materials in value-added products.

Ikondo is one of the wards in Njombe Region, Tanzania. The ward is endowed with sufficient rains and heavy rainfall in some months of the rainy season. This makes it good for growing varieties of crops. It was learnt that most of these products or crops are sold raw. If processed, by-products of these crops could have been sold at some added values, more employment opportunities could be created and the household income would increase. As a result, small scale farmers would generate higher incomes which in turn would improve their livelihood. But processing every crop may prove to be difficult. Thus, a crop cutting across all the criteria was considered in the ward.

Results of this study will assist policymakers to formulate guidelines/policies for agricultural activities at Ikondo Ward to improve quality crop production in the ward. Upon implementation of such policies, the household income is expected to increase, and hence improve the livelihood of families in the ward. More employment opportunities will also be created. The increase in production of a particular crop attracts investment in agro-processing industries like cooking oil refineries and cereal milling machines. To the best of knowledge, none of the above studies has been done to evaluate and prioritise crops for processing, particularly at Ikondo Ward using the fuzzy WASPAS method. Thus, the fuzzy WASPAS method was applied in the methodology.

The rest of the paper is organized as follows: description and application of the fuzzy WASPAS method, Results and discussion and finally a conclusion is presented.

\section{The Fuzzy WASPAS Method \\ Steps for the fuzzy WASPAS method}

Weighted Aggregated Sum Product Assessment (WASPAS) method is a special combination of two MCDM methods; the Weighted Sum Method (WSM) and the Weighted Product Method (WPM) (Chakraborty et al. 2015). Steps are suggested in applying the WASPAS method. Ignoring some steps carried out in the field, WASPAS method begins with a decision matrix. But to carry out a field project and apply the fuzzy WASPAS method, nine steps were suggested;

Step 1: Formation of a decision-making committee: The committee $D=$ $\left\{D_{1}, D_{2}, \cdots, D_{K}\right\}$ of $K$ decisionmakers who are experts in the area of interest is formed.

Step 2: Identification of the evaluation criteria and the assessment alternatives: Set $C=\left\{C_{1}, C_{2}, \cdots, C_{n}\right\}$ of $n$ evaluation criteria is identified and the set $A=\left\{A_{1}, A_{2}, \cdots, A_{m}\right\} \quad$ of $\quad m$ alternatives under the study is given.

Step 3: Choices of appropriate linguistic variables to assign the importance weight of each criterion and linguistic variables for ratings of each alternative.

Step 4: Aggregation of the importance weights and pooling together experts' ratings on alternatives:

The importance weights assigned by the individual experts are aggregated for each criterion to get the aggregated fuzzy weight $\widetilde{\boldsymbol{w}}_{j}$ for each $C_{j}, j=1,2, \cdots, n$. This is done as follows: 
Suppose $\quad \widetilde{w}_{j l}=\left(w_{j l 1}, w_{j l 2}, w_{j l 3}\right) \quad$ is the importance fuzzy weight assigned to criterion $j$ by expert $l ; l=1,2, \cdots, K$.

Then, the aggregated fuzzy weight for criterion $j$ is $\widetilde{\boldsymbol{w}}_{j}=\left(w_{j 1}, w_{j 2}, w_{j 3}\right)$, where,

$$
\left\{\begin{array}{l}
w_{j 1}=\frac{1}{K} \sum_{l=1}^{K} w_{j l 1} \\
w_{j 2}=\frac{1}{K} \sum_{l=1}^{K} w_{j l 2} \\
w_{j 3}=\frac{1}{K} \sum_{l=1}^{K} w_{j l 3}
\end{array}\right.
$$

for each $C_{j}$. Thus, for all criteria,

$$
\widetilde{w}=\left[\widetilde{\boldsymbol{w}}_{1}, \widetilde{\boldsymbol{w}}_{2}, \cdots, \widetilde{\boldsymbol{w}}_{n}\right]^{T}
$$

There are several other means of obtaining fuzzy importance weights of criteria. Two of them are fuzzy AHP method and the linear weight method (Tesic et al. 2018).

Similarly, the decision-makers (experts) ratings are pooled together to come up with the aggregated fuzzy rating $\widetilde{\boldsymbol{x}}_{i j}$ for each alternative $A_{i}, i=1,2, \cdots, m$ for each criterion $C_{j}$.

Let $\tilde{\boldsymbol{x}}_{i j l}=\left(x_{i j l 1}, x_{i j l 2}, x_{i j l 3}\right)$ be a fuzzy rating by decision-maker $l$ on a criterion $C_{j}$ for alternative $A_{i}, i=1,2, \cdots, m$.

Then, $\tilde{\boldsymbol{x}}_{i j}=\left(x_{i j 1}, x_{i j 2}, x_{i j 3}\right)$ is the aggregated fuzzy rating of alternative $A_{i}$ on criterion $C_{j}$, where,

$$
\left\{\begin{array}{l}
x_{i j 1}=\frac{1}{K} \sum_{l=1}^{K} x_{i j l 1} \\
x_{i j 2}=\frac{1}{K} \sum_{l=1}^{K} x_{i j l 2} \\
x_{i j 3}=\frac{1}{K} \sum_{l=1}^{K} x_{i j l 3}
\end{array}\right.
$$

for each $C_{j}$ on each $A_{i}$.

NB.: This aggregation procedure of the importance fuzzy weights and the fuzzy ratings is not the only approach, there are other approaches too. It is slightly different for trapezoidal fuzzy numbers.

Step 5: Construction of fuzzy decision matrix and normalised fuzzy decision matrix:
All $\tilde{\boldsymbol{x}}_{i j} \mathrm{~s}$ in step 4 above are collected and systematically are written in matrix form such that

$$
\tilde{X}=\left[\begin{array}{cccc}
\widetilde{\boldsymbol{x}}_{11} & \widetilde{\boldsymbol{x}}_{12} & \ldots & \widetilde{\boldsymbol{x}}_{1 n} \\
\widetilde{\boldsymbol{x}}_{21} & \widetilde{\boldsymbol{x}}_{22} & \ldots & \widetilde{\boldsymbol{x}}_{2 n} \\
\vdots & \vdots & \ddots & \vdots \\
\widetilde{\boldsymbol{x}}_{m 1} & \widetilde{\boldsymbol{x}}_{m 2} & \ldots & \widetilde{\boldsymbol{x}}_{m n}
\end{array}\right]
$$

This is the fuzzy decision matrix. Columns are along with criteria, while rows are along with alternatives.

The matrix above is normalised so that

- Each entry of the normalised triangular fuzzy numbers belongs to $[0,1]$, and

- The linear scale transformation makes criteria scales into comparable quantities.

The normalised fuzzy decision matrix is an $m \times n$ matrix given by

$$
\tilde{R}=\left[\begin{array}{cccc}
\tilde{\boldsymbol{r}}_{11} & \tilde{\boldsymbol{r}}_{12} & \ldots & \tilde{\boldsymbol{r}}_{1 n} \\
\tilde{\boldsymbol{r}}_{21} & \tilde{\boldsymbol{r}}_{22} & \ldots & \tilde{\boldsymbol{r}}_{2 n} \\
\vdots & \vdots & \ddots & \vdots \\
\tilde{\boldsymbol{r}}_{m 1} & \tilde{\boldsymbol{r}}_{m 2} & \ldots & \tilde{\boldsymbol{r}}_{m n}
\end{array}\right]
$$

If $C_{j}$ is a benefit criterion then,

$$
\tilde{\boldsymbol{r}}_{i j}=\left(\frac{x_{i j 1}}{c_{j}^{*}}, \frac{x_{i j 2}}{c_{j}^{*}}, \frac{x_{i j 3}}{c_{j}^{*}}\right)
$$

If $C_{j}$ is a cost criterion then

$$
\tilde{\boldsymbol{r}}_{i j}=\left(\frac{a_{j}^{-}}{x_{i j 3}}, \frac{a_{j}^{-}}{x_{i j 2}}, \frac{a_{j}^{-}}{x_{i j 1}}\right)
$$

where,

$c_{j}^{*}=\max _{i}\left\{x_{i j 3}\right\}, j$ is a benefit criterion.

$a_{j}^{-}=\min _{i}\left\{x_{i j 1}\right\}, j$ is a non-benefit (cost) criterion.

Step 6: Construction of Weighted Normalised Fuzzy Decision Matrix:

The importance weight of each criterion in Equation (2) is now considered. The weighted normalised decision matrix $\tilde{V}$ is in two forms; one with entries in the form of WSM and the other one in WPM.

Thus

$$
\tilde{V}_{W S M}=\left[\begin{array}{cccc}
\widetilde{\boldsymbol{v}}_{11} & \widetilde{\boldsymbol{v}}_{12} & \ldots & \widetilde{\boldsymbol{v}}_{1 n} \\
\widetilde{\boldsymbol{v}}_{21} & \widetilde{\boldsymbol{v}}_{22} & \ldots & \widetilde{\boldsymbol{v}}_{2 n} \\
\vdots & \vdots & \ddots & \vdots \\
\widetilde{\boldsymbol{v}}_{m 1} & \widetilde{\boldsymbol{v}}_{m 2} & \ldots & \widetilde{\boldsymbol{v}}_{m n}
\end{array}\right]
$$




$$
\begin{aligned}
& \tilde{V}_{W P M}=\left[\begin{array}{cccc}
\widetilde{\boldsymbol{p}}_{11} & \widetilde{\boldsymbol{p}}_{12} & \ldots & \widetilde{\boldsymbol{p}}_{1 n} \\
\widetilde{\boldsymbol{p}}_{21} & \widetilde{\boldsymbol{p}}_{22} & \ldots & \widetilde{\boldsymbol{p}}_{2 n} \\
\vdots & \vdots & \ddots & \vdots \\
\widetilde{\boldsymbol{p}}_{m 1} & \widetilde{\boldsymbol{p}}_{m 2} & \ldots & \widetilde{\boldsymbol{p}}_{m n}
\end{array}\right] \\
& \widetilde{\boldsymbol{v}}_{i j}=\tilde{\boldsymbol{r}}_{i j}(\cdot) \widetilde{\boldsymbol{w}}_{j} \text { for WSM } \\
& \widetilde{\boldsymbol{p}}_{i j}=\tilde{\boldsymbol{r}}_{i j} \widetilde{\boldsymbol{w}}_{j} \quad \text { for WPM }
\end{aligned}
$$

Step 7: Determination of the joint criterion of optimality function:

These are values of the optimality function. By Chakraborty et al. (2015), there are two optimality functions; one is based on WSM $\widetilde{Q}_{i}=\left(q_{1 i}, q_{2 i}, q_{3 i}\right)$ and the other one based on WPM $\tilde{P}_{i}=\left(p_{1 i}, p_{2 i}, p_{3 i}\right)$. Each is the total relative importance of $i^{\text {th }}$ alternative.

Thus,

$\tilde{Q}_{i}=\sum_{j=1}^{n} \widetilde{\boldsymbol{v}}_{i j}, i=1, \cdots, m$ for WSM and

$\tilde{P}_{i}=\sum_{j=1}^{n} \widetilde{\boldsymbol{p}}_{i j}, i=1, \cdots, m$ for WPM

The fuzzy values of the joint optimality function $\tilde{Q}_{i}$ and $\tilde{P}_{i}$ were defuzzified by the centre of area method to obtain the crisp values $Q_{i}$ and $P_{i}$ for each alternative.

$$
\begin{aligned}
Q_{i} & =\frac{1}{3}\left(q_{1 i}+q_{2 i}+q_{3 i}\right) \\
P_{i} & =\frac{1}{3}\left(p_{1 i}+p_{2 i}+p_{3 i}\right)
\end{aligned}
$$

Step 8: Determination of integrated (general) utility function value:

The integrated utility function value $K_{i}$ of the WASPAS method for each alternative (Turskis et al. 2015) which is also known as generalised total relative importance of the $i^{\text {th }}$ alternative (Chakraborty et al. 2015) was determined as follows:

$$
K_{i}=\lambda Q_{i}+(1-\lambda) P_{i}
$$

For $0 \leq \lambda \leq 1$ and

$$
\lambda\left(\sum_{i=1}^{m} Q_{i}+\sum_{i=1}^{m} P_{i}\right)=\sum_{i=1}^{m} P_{i}
$$

It can be observed that when $\lambda=0$, WASPAS becomes WPM, and when $\lambda=1$, WASPAS is reduced to WSM.

Step 9: Ranking the alternatives.

The ranking is done based on $K$ values. The higher value of $K$ implies a higher rank.

\section{Fuzzy WASPAS in selecting crops for agro-processing at Ikondo Ward \\ Data collection}

It was observed that, Ikondo Ward grows different varieties of crops. Due to the complexity of the mathematical models involved, only five most grown crops were considered. These were maize $\left(A_{1}\right)$, beans $\left(A_{2}\right)$, tea leaves $\left(A_{3}\right)$, sunflower seeds $\left(A_{4}\right)$ and bananas $\left(A_{5}\right)$. The crops are grown by the majority of the people in the ward. The regional officer responsible for agriculture and extension services facilitated the exercise of identifying the crops. Eight criteria related to crop production and the linguistic variables (for the rating of the crops) were prepared in advance. The chosen criteria were assumed to be the most important key factors for crop production to small scale farmers. But one may consider different criteria deemed useful for crop production leading to the promotion of agro-processing and carry out research on that. Linguistic variables for assigning the importance of each criterion were also prepared. As it was stated earlier, some eight useful criteria for the study were considered (Table 1). They were labelled as $C_{n}$ for $n=1,2, \cdots, 8$.

Three decision-makers who are also experts in the agricultural sector in Njombe Region participated and were asked to provide their preferences as to the importance of each criterion using the linguistic terms (variables) shown (Table 2).

A criterion compared to itself or if two criteria were equally important were assigned $(1,1,1)$. If criterion $C_{i}$ is compared to a criterion $C_{j}, i \neq j$ as $(a, b, c)$ then comparison of $C_{j}$ to $C_{i}$ is $(a, b, c)^{-1}=\left(\frac{1}{c}, \frac{1}{b}, \frac{1}{a}\right)$.

Also, the three experts were supposed to provide their preferences by rating the alternatives (crops) using the linguistic variables shown in Table 3 . 
Table 1: Criteria for the study

\begin{tabular}{|c|c|c|}
\hline Label & Criteria & Explanation (if any) \\
\hline$C_{1}$ & Availability of farm inputs & seeds/seedlings, fertilizers, pesticides \\
\hline$C_{2}$ & Affordability of farm inputs & seeds/seedlings, fertilizers, pesticides \\
\hline$C_{3}$ & Farm management costs & $\begin{array}{l}\text { clearing/ploughing the land, planting/transplanting, } \\
\text { weeding }\end{array}$ \\
\hline$C_{4}$ & $\begin{array}{l}\text { Availability } \\
\text { technical/technology } \\
\text { extension services }\end{array}$ & $\begin{array}{l}\text { means of farm preparation, assistance from } \\
\text { agricultural extension officers }\end{array}$ \\
\hline$C_{5}$ & $\begin{array}{l}\text { Crop resistance to pests and } \\
\text { diseases }\end{array}$ & \\
\hline$C_{6}$ & $\begin{array}{l}\text { Crop adaptability to the } \\
\text { prevailing conditions }\end{array}$ & drought, weather changes \\
\hline$C_{7}$ & $\begin{array}{l}\text { The extent to which the crop is } \\
\text { susceptible to rodents and stalk } \\
\text { borers }\end{array}$ & \\
\hline$C_{8}$ & $\begin{array}{l}\text { Yield, marketability } \\
\text { profitability of the crop }\end{array}$ & \\
\hline
\end{tabular}

Table 2: Linguistic variables for importance weight of criteria

\begin{tabular}{|cccccc|}
\hline $\begin{array}{c}\text { Linguistic } \\
\text { variable } \\
\text { fuzzy number }\end{array}$ & NI & SI & MI & I & VI \\
\hline
\end{tabular}

Key: NI $\equiv$ Not Important; SI $\equiv$ Slightly Important; MI $\equiv$ Moderately Important; I $\equiv$ Important; VI $\equiv$ Very Important.

Table 3: Linguistic variables for rating alternatives against criteria

\begin{tabular}{|cccccc|}
\hline $\begin{array}{c}\text { Linguistic variable } \\
\text { Fuzzy number }\end{array}$ & VP & $\mathbf{P}$ & $\mathbf{M G}$ & $\mathbf{G}$ & $\mathbf{V G}$ \\
& $(1,1,3)$ & $(1,3,5)$ & $(3,5,7)$ & $(5,7,9)$ & $(7,9,9)$ \\
\hline
\end{tabular}

Key: VP $\equiv$ Very Poor; $\mathbf{P} \equiv$ Poor; MG $\equiv$ Medium Good; $\mathbf{G} \equiv$ Good; VI $\equiv$ Very good.

Applying the fuzzy WASPAS method

Determination of weights of criteria by fuzzy TOPSIS method

Aggregation of the experts' preferences on the importance weight of criteria:

The importance weights assigned by the experts on each criterion in Table 4 were aggregated using triangular fuzzy numbers in Table 2 and Equation (1) to obtain the aggregated fuzzy weight $\widetilde{\boldsymbol{w}}_{j}$ of criterion $C_{j}$. The experts' ratings on each crop were also pooled together to get the aggregated fuzzy rating $\widetilde{\boldsymbol{x}}_{i j}$ of crop $A_{i}$ under criterion $C_{j}$.

Table 4: Assignment of the importance weight of criteria by experts

\begin{tabular}{|cccc|}
\hline Criteria & $D_{1}$ & $D_{2}$ & $D_{3}$ \\
$C_{1}$ & $V I$ & $V I$ & $V I$ \\
$C_{2}$ & $I$ & $M I$ & $I$ \\
$C_{3}$ & $M I$ & $V I$ & $I$ \\
$C_{4}$ & $M I$ & $V I$ & $I$ \\
$C_{5}$ & $I$ & $V I$ & $I$ \\
$C_{6}$ & $M I$ & $I$ & $M I$ \\
$C_{7}$ & $I$ & $I$ & $I$ \\
$C_{8}$ & $I$ & $V I$ & $I$ \\
\hline
\end{tabular}


Consider Table 4 and Equation (1). For criterion $C_{3}$ as an example, experts $D_{1}, D_{2}$, and $D_{3}$ assigned $M I, V I$, and $I$, respectively as their preferences for the criterion. By Table 2;
$M I=(0.3,0.5,0.7)$,
$V I=(0.7,0.9,0.9)$,
$I=(0.5,0.7,0.9)$

Thus, $\widetilde{\boldsymbol{w}}_{3}=\left(w_{31}, w_{32}, w_{33}\right)$,

where,

Hence;

$$
\begin{gathered}
w_{31}=\frac{1}{3}(0.3+0.7+0.5)=0.5 \\
w_{32}=\frac{1}{3}(0.5+0.9+0.7)=0.7 \\
w_{33}=\frac{1}{3}(0.7+0.9+0.9)=0.8333
\end{gathered}
$$

$$
\widetilde{\boldsymbol{w}}_{3}=(0.5,0.7,0.8333)
$$

In the same manner, importance weights for other criteria $\widetilde{\boldsymbol{w}}_{1}, \widetilde{\boldsymbol{w}}_{2}, \cdots, \widetilde{\boldsymbol{w}}_{8}$ are computed.

Therefore,

$$
W=\left[\begin{array}{c}
\widetilde{\boldsymbol{w}}_{1} \\
\widetilde{\boldsymbol{w}}_{2} \\
\widetilde{\boldsymbol{w}}_{3} \\
\widetilde{\boldsymbol{w}}_{4} \\
\widetilde{\boldsymbol{w}}_{5} \\
\widetilde{\boldsymbol{w}}_{6} \\
\widetilde{\boldsymbol{w}}_{7} \\
\widetilde{\boldsymbol{w}}_{8}
\end{array}\right]=\left[\begin{array}{c}
(0.7,0.9,0.9) \\
(0.4333,0.6333,0.8333) \\
(0.5,0.7,0.8333) \\
(0.5,0.7,0.8333) \\
(0.5667,0.7667,0.9) \\
(0.3667,0.5667,0.7667) \\
(0.5,0.7,0.9) \\
(0.5667,0.7667,0.9)
\end{array}\right]
$$

\section{Determination of decision matrix}

By Equation (3) and Table 3, the experts' assessments in Table 5 were pooled together to come up with a decision matrix (Table 6).

Table 5: Assessment of crops by experts: Ikondo Ward

\begin{tabular}{|cccccccccc|}
\hline & $D M$ & $C_{1}$ & $C_{2}$ & $C_{3}$ & $C_{4}$ & $C_{5}$ & $C_{6}$ & $C_{7}$ & $C_{8}$ \\
& $D_{1}$ & $G$ & $M G$ & $G$ & $G$ & $M G$ & $G$ & $G$ & $G$ \\
Maize $A_{1}$ & $D_{2}$ & $M G$ & $G$ & $G$ & $M G$ & $M G$ & $M G$ & $G$ & $M G$ \\
& $D_{3}$ & $G$ & $G$ & $M G$ & $G$ & $M G$ & $M G$ & $M G$ & $V G$ \\
& $D_{1}$ & $G$ & $M G$ & $G$ & $G$ & $M G$ & $M G$ & $M G$ & $G$ \\
Beans $A_{2}$ & $D_{2}$ & $M G$ & $M G$ & $M G$ & $M G$ & $M G$ & $M G$ & $M G$ & $M G$ \\
& $D_{3}$ & $G$ & $G$ & $M G$ & $G$ & $V G$ & $G$ & $P$ & $V G$ \\
Tea leaves & $D_{1}$ & $G$ & $G$ & $M G$ & $G$ & $G$ & $G$ & $M G$ & $M G$ \\
$A_{3}$ & $D_{2}$ & $M G$ & $G$ & $G$ & $M G$ & $M G$ & $M G$ & $G$ & $M G$ \\
& $D_{3}$ & $G$ & $V G$ & $G$ & $M G$ & $P$ & $M G$ & $V P$ & $V G$ \\
Sunflower & $D_{1}$ & $M G$ & $M G$ & $G$ & $M G$ & $M G$ & $M G$ & $M G$ & $M G$ \\
seeds $A_{4}$ & $D_{2}$ & $M G$ & $M G$ & $G$ & $M G$ & $M G$ & $M G$ & $G$ & $M G$ \\
& $D_{3}$ & $G$ & $M G$ & $G$ & $M G$ & $V G$ & $G$ & $V P$ & $V G$ \\
& $D_{1}$ & $G$ & $M G$ & $M G$ & $M G$ & $G$ & $M G$ & $M G$ & $G$ \\
Bananas $A_{5}$ & $D_{2}$ & $M G$ & $M G$ & $G$ & $G$ & $M G$ & $M G$ & $G$ & $M G$ \\
& $D_{3}$ & $M G$ & $M G$ & $G$ & $G$ & $V G$ & $G$ & $P$ & $V G$ \\
\hline
\end{tabular}


Table 6: The decision matrix for Ikondo Ward

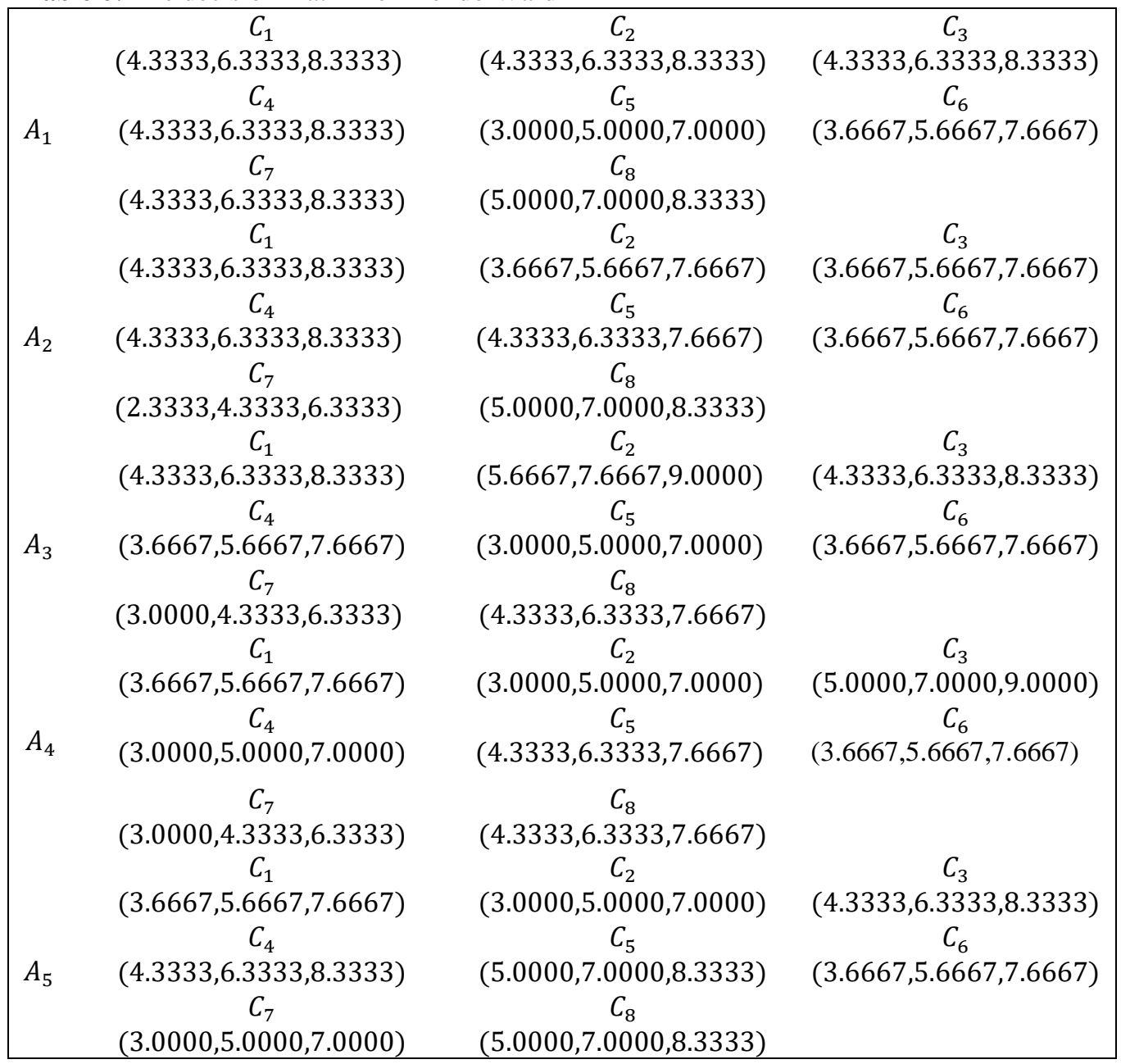

Determination of the normalised decision matrix

Using the decision matrix in Table 6, the fuzzy WASPAS requires normalisation of the decision matrix. By Equations (6) and (7), each column of criterion is normalised. Recall that all criteria in Table 1 are non-cost criteria except criterion $C_{3}$.

Hence the computed normalised decision matrix is in Table 7. 
Table 7: The normalised decision matrix for Ikondo Ward

\begin{tabular}{|c|c|c|c|}
\hline$A_{1}$ & $\begin{array}{c}C_{1} \\
(0.5200,0.7600,1.0000) \\
C_{4} \\
(0.5200,0.7600,1.0000) \\
C_{7} \\
(0.5200,0.7600,1.0000)\end{array}$ & $\begin{array}{c}C_{2} \\
(0.4815,0.7037,0.9259) \\
C_{5} \\
(0.3600,0.6000,0.8400) \\
C_{8} \\
(0.60000 .84001 .0000)\end{array}$ & $\begin{array}{c}C_{3} \\
(0.4400,0.5790,0.8462) \\
C_{6} \\
(0.4783,0.7391,1.0000)\end{array}$ \\
\hline$A_{2}$ & $\begin{array}{c}C_{1} \\
(0.5200,0.7600,1.0000) \\
C_{4} \\
(0.5200,0.7600,1.0000) \\
C_{7} \\
(0.2800,0.5200,0.7600)\end{array}$ & $\begin{array}{c}C_{2} \\
(0.4074,0.6296,0.8519) \\
C_{5} \\
(0.5200,0.7600,0.9200) \\
C_{8} \\
(0.60000 .84001 .0000)\end{array}$ & $\begin{array}{c}C_{3} \\
(0.4783,0.6471,1.0000) \\
C_{6} \\
(0.4783,0.7391,1.0000)\end{array}$ \\
\hline$A_{3}$ & $\begin{array}{c}C_{1} \\
(0.5200,0.7600,1.0000) \\
C_{4} \\
(0.4400,0.6800,0.9200) \\
C_{7} \\
(0.3600,0.5200,0.7600)\end{array}$ & $\begin{array}{c}C_{2} \\
(0.6296,0.8519,1.0000) \\
C_{5} \\
(0.3600,0.6000,0.8400) \\
C_{8} \\
(0.52000 .76000 .9200)\end{array}$ & $\begin{array}{c}C_{3} \\
(0.4400,0.5790,0.8462) \\
C_{6} \\
(0.4783,0.7391,1.0000)\end{array}$ \\
\hline$A_{4}$ & $\begin{array}{c}C_{1} \\
(0.4400,0.6800,0.9200) \\
C_{4} \\
(0.3600,0.6000,0.8400) \\
C_{7} \\
(0.3600,0.5200,0.7600)\end{array}$ & $\begin{array}{c}C_{2} \\
(0.3333,0.5556,0.7778) \\
C_{5} \\
(0.5200,0.7600,0.9200) \\
C_{8} \\
(0.52000 .76000 .9200)\end{array}$ & $\begin{array}{c}C_{3} \\
(0.4074,0.5238,0.7333) \\
C_{6} \\
(0.4783,0.7391,1.0000)\end{array}$ \\
\hline$A_{5}$ & $\begin{array}{c}C_{1} \\
(0.4400,0.6800,0.9200) \\
C_{4} \\
(0.5200,0.7600,1.0000) \\
C_{7} \\
(0.3600,0.6000,0.8400)\end{array}$ & $\begin{array}{c}C_{2} \\
(0.3333,0.5556,0.7778) \\
C_{5} \\
(0.6000,0.8400,1.0000) \\
C_{8} \\
(0.6000 \quad 0.84001 .0000)\end{array}$ & $\begin{array}{c}C_{3} \\
(0.4400,0.5790,0.8462) \\
C_{6} \\
(0.4783,0.7391,1.0000)\end{array}$ \\
\hline
\end{tabular}

Determination of the weighted normalised decision matrix for WSM

By the Equation (10) and the fuzzy importance weights in Equation (18) each entry of the weighted decision matrix by the WSM is determined. 
Table 8: The weighted normalised decision matrix for Ikondo Ward (for WSM)

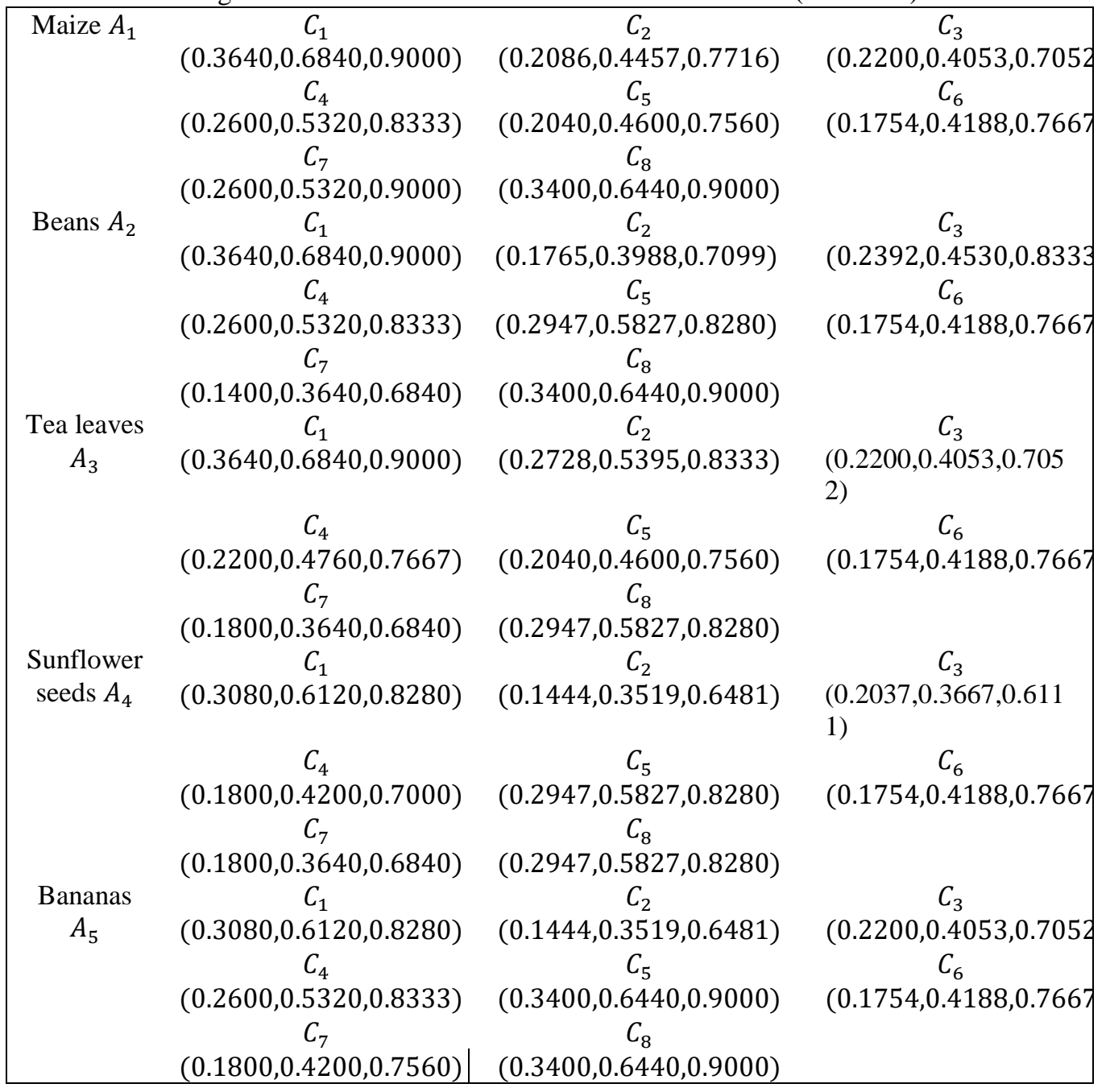

Determination of the weighted normalised decision matrix for WPM

By the Equation (11) and the fuzzy importance weights in Equation (18) each entry of the weighted decision matrix by the WPM is determined (Table 9). 
Table 9: The weighted normalised decision matrix for Ikondo Ward (for WPM)

\begin{tabular}{|c|c|c|c|}
\hline$A_{1}$ & $\begin{array}{c}C_{1} \\
(0.6327,0.7811,1.0000) \\
C_{4} \\
(0.7211,0.8252,1.0000) \\
C_{7} \\
(0.7211,0.8252,1.0000)\end{array}$ & $\begin{array}{c}C_{2} \\
(0.7285,0.8005,0.9379) \\
C_{5} \\
(0.5605,0.6760,0.8548) \\
C_{8} \\
(0.7487,0.8749,1.0000)\end{array}$ & $\begin{array}{c}C_{3} \\
(0.6633,0.6821,0.8701) \\
C_{6} \\
(0.7630,0.8426,1.0000)\end{array}$ \\
\hline$A_{2}$ & $\begin{array}{c}C_{1} \\
(0.6327,0.7811,1.0000) \\
C_{4} \\
(0.7211,0.8252,1.0000) \\
C_{7} \\
(0.5292,0.6327,0.7811)\end{array}$ & $\begin{array}{c}C_{2} \\
(0.6777,0.7460,0.8749) \\
C_{5} \\
(0.6904,0.8103,0.9277) \\
C_{8} \\
(0.7487,0.8749,1.0000)\end{array}$ & $\begin{array}{c}C_{3} \\
(0.6916,0.7374,1.0000) \\
C_{6} \\
(0.7630,0.8426,1.0000)\end{array}$ \\
\hline$A_{3}$ & $\begin{array}{c}C_{1} \\
(0.6327,0.7811,1.0000) \\
C_{4} \\
(0.6633,0.7634,0.9329) \\
C_{7} \\
(0.6000,0.6327,0.7811)\end{array}$ & $\begin{array}{c}C_{2} \\
(0.8183,0.9034,1.0000) \\
C_{5} \\
(0.5605,0.6760,0.8548) \\
C_{8} \\
(0.6904,0.8103,0.9277)\end{array}$ & $\begin{array}{c}C_{3} \\
(0.6633,0.6821,0.8701) \\
C_{6} \\
(0.7630,0.8426,1.0000)\end{array}$ \\
\hline$A_{4}$ & $\begin{array}{c}C_{1} \\
(0.5629,0.7067 \\
0.9277) \\
C_{4} \\
(0.6000,0.6994,0.8648) \\
C_{7} \\
(0.6000,0.6327,0.7811)\end{array}$ & $\begin{array}{c}C_{2} \\
(0.6212,0.6892 \\
0.8110) \\
C_{5} \\
(0.6904,0.8103,0.9277) \\
C_{8} \\
(0.6904,0.8103,0.9277)\end{array}$ & $\begin{array}{c}C_{3} \\
(0.6383,0.6359 \\
0.7722) \\
C_{6} \\
(0.7630,0.8426,1.0000)\end{array}$ \\
\hline$A_{5}$ & $\begin{array}{c}C_{1} \\
(0.5629,0.7067,0.9277) \\
C_{4} \\
(0.7211,0.8252,1.0000) \\
C_{7} \\
(0.6000,0.6994,0.8548)\end{array}$ & $\begin{array}{c}C_{2} \\
(0.6212,0.6892,0.8110) \\
C_{5} \\
(0.7487,0.8749,1.0000) \\
C_{8} \\
(0.7487,0.8749,1.0000)\end{array}$ & $\begin{array}{c}C_{3} \\
(0.6633,0.6821,0.8701) \\
C_{6} \\
(0.7630,0.8426,1.0000)\end{array}$ \\
\hline
\end{tabular}

Determination of fuzzy values of optimality function for the ranks

Applying Equations (12) and (13), the values of optimality function were determined (Table 10).

Table 10: Fuzzy values of the optimality function

\begin{tabular}{|cccc|}
\hline$\tilde{Q}$ & $A_{1}$ & $A_{2}$ & $A_{3}$ \\
& $(2.0320,4.1218,6.5328)$ & $(1.9898,4.0773,6.4552)$ & $(1.9309,3.9303,6.239$ \\
& $A_{4}$ & $A_{5}$ & \\
$\tilde{P}_{i}$ & $(1.7809,3.6988,5.8939)$ & $(1.9678,4.0280,6.3373)$ & $A_{3}$ \\
& $A_{1}$ & $A_{2}$ & $(0.0404,0.1073,0.502$ \\
& $(0.0509,0.1447,0.6976)$ & $(0.0446,0.1340,0.6340)$ & \\
& $A_{4}$ & $A_{5}$ & \\
& $(0.0292,0.0758,0.3378)$ & $(0.0429,0.1237,0.5596)$ &
\end{tabular}

The determined fuzzy values of $\tilde{Q}_{i}$ and $\tilde{P}_{i}$ were defuzzified by Equations (14) and (15), respectively to obtain the crisp values Qi and Pi. Concomitantly, the constant $\lambda$ was also found using Equation (17). The $K_{i}$ values for ranking the alternatives were calculated by Equation (16). All are summarised in Table 11. 
Table 11: Defuzzified values of the optimality function

\begin{tabular}{|ccccccc|}
\hline & $A_{1}$ & $A_{2}$ & $A_{3}$ & $A_{4}$ & $A_{5}$ & $\lambda$ \\
$Q_{i}$ & 4.2289 & 4.1741 & 4.0337 & 3.7912 & 4.1110 & \\
$P_{i}$ & 0.2977 & 0.2709 & 0.2168 & 0.1476 & 0.2421 & 0.0546 \\
$K_{i}$ & 0.5124 & 0.4841 & 0.4253 & 0.3466 & 0.4534 & \\
Ranking & 1 & 2 & 4 & 5 & 3 & \\
\hline
\end{tabular}

\section{Results and Discussion}

The fuzzy importance weights in Equation (18) can be defuzzified by the centre of area method into crisp values for easy comparisons. $w_{j}=\frac{1}{3}\left(w_{1 j}+w_{2 j}+w_{3 j}\right) \quad$ for $\quad \widetilde{\boldsymbol{w}}_{j}=$ $\left(w_{1 j}, w_{2 j}, w_{3 j}\right)$ and $j=1, \cdots, n$

Thus, all defuzzified crisp weights of fuzzy importance weights of the criteria are found in Table 12.

Table 12: Defuzzified fuzzy importance weights

\begin{tabular}{|lcccccccc|}
\hline Crisp & $\boldsymbol{w}_{\mathbf{1}}$ & $\boldsymbol{w}_{\mathbf{2}}$ & $\boldsymbol{w}_{\mathbf{3}}$ & $\boldsymbol{w}_{\mathbf{4}}$ & $\boldsymbol{w}_{\mathbf{5}}$ & $\boldsymbol{w}_{\mathbf{6}}$ & $\boldsymbol{w}_{\mathbf{7}}$ & $\boldsymbol{w}_{\mathbf{8}}$ \\
Weights & 0.8333 & 0.6333 & 0.6778 & 0.6778 & 0.7445 & 0.5667 & 0.7000 & 0.74 \\
Rank & 1 & 7 & 5.5 & 5.5 & 2.5 & 8 & 4 & 2.5 \\
\hline
\end{tabular}

Criterion $C_{1}$ (availability of farm inputs) scored the highest in weight (Table 12). It means that farm inputs such as seeds, fertilizers and pesticides are available. By the same table, $C_{5}$ (Crop resistance to pests and diseases) had the lowest weight. $C_{2}$ (Affordability of farm inputs) is the second from the lowest. This means, for reasons not known, there are difficulties in obtaining farm inputs. Other criteria are as they are symbolically seen in the table (Table 12) with their meaning found in Table 1 . The ranking of crops (Table 11) and the order of crops (Table 8); maize ranks the highest (1), beans ranks second (2), tea leaves ranks third (3), in the fourth rank (4) are sunflower seeds, while in the fifth rank (5) are bananas according $K_{i}$ values (Figure 1).

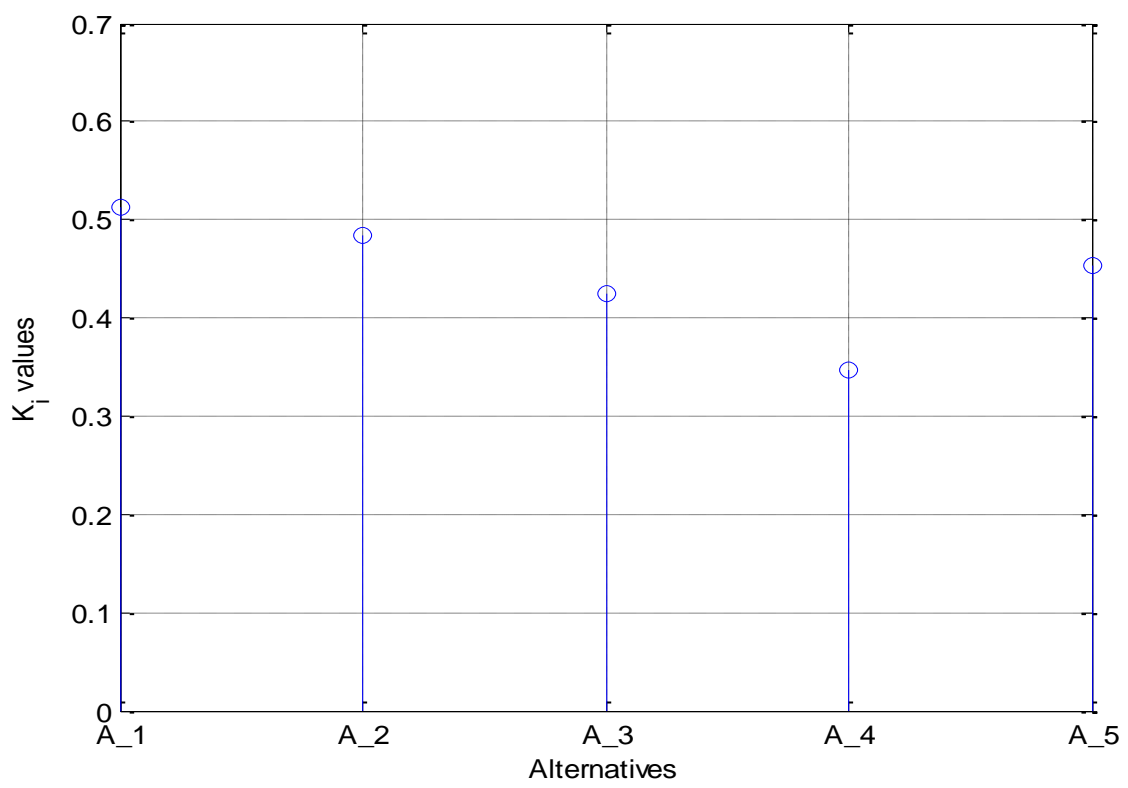

Figure 1: Comparison of $K_{i}$ values for ranking the alternatives at Ikondo Ward. 
One may note that sunflower seeds are for cooking oil but ranked low at Ikondo Ward. Since currently there is a shortage of cooking oil in Tanzania, deliberate measures should be taken to raise the production of sunflower seeds. These may include the provision of free farm inputs like seeds, fertilizers and pesticides and technical as well as technological support. It can also be pointed out that maize and beans rank higher than any other crop since these are staple foods. Everybody should produce food. Seeds are commercially and locally available. In some areas, fertilizers or/and pesticides are not necessarily needed. It means that maize and beans can easily be produced in such areas. Maize was selected as crop number one for processing followed by beans.

\section{Conclusion}

To every action or option, there exist several alternatives. Individuals and organisations require some attributes for the choice or selection of a particular item, action or option. Several MCDM methods have been developed. In this paper, a step-by-step procedure has been taken to apply fuzzy WASPAS method in real-life decision making. A case study was used in applying the fuzzy WASPAS method. Weights of criteria were determined by fuzzy TOPSIS method. Fuzzy WASPAS successfully ranked the crops. Maize ranked the highest among the five crops (the alternatives) and therefore proposed to grow most for agro-processing.

In future, either one may develop a fuzzy WASPAS method whereby weights of criteria are determined by other methods like the fuzzy AHP or use other newly developed methods including Priority Pointing Procedure (PPP). Also, other useful criteria in crop production may be considered to rank the same or different crops at the ward. Similarly, the study can be replicated to other crops and/or be extended in other geographical locations or regions.

\section{References}

Badalpur M and Nurbakhsh E 2019 An application of WASPAS method in risk qualitative analysis: a case study of a road construction project in Iran. Int. J. Const. Manage. 1-9.

Chakraborty S and Zavadskas EK 2014 Applications of WASPAS method in manufacturing decision making. Informatica 25(1): 1-20.

Chakraborty S, Zavadskas EK and Antucheviciene J 2015 Applications of WASPAS method as a multi-criteria decision-making tool. Economic Computation and Economic Cybernetics Studies and Research 49(1): 5-22.

Chandrawati TB, Ratna AAP and Sari RF 2020 Path selection using fuzzy weight aggregated sum product assessment. Int. J. Comp. Commun. Control 15(5).

Da Silva CA 2009 Agro-industries for development, CABI.

Dhiman HS, Deb D, Muresan V and Unguresan ML 2019 Multi-criteria decision making approach for hybrid operation of wind farms. Symmetry 11(5): 675.

Ighravwe DE and Oke SA 2017 A fuzzygrey-weighted aggregate sum product assessment methodical approach for multi-criteria analysis of maintenance performance systems. Int. J. Syst. Assur. Eng. Manage. 8(2): 961-973.

Keshavarz-Ghorabaee M, Amiri M, HashemiTabatabaei M, Zavadskas EK and Kaklauskas A 2020 A new decisionmaking approach based on fermatean fuzzy sets and WASPAS for green construction supplier evaluation. Maths. 8(12): 2202.

Kumar R, Bhattacherjee A, Singh AD, Singh S and Pruncu CI 2020 Selection of portable hard disk drive based upon weighted aggregated sum product assessment method: A case of Indian market. Meas. Cont. 53(7-8): 1218-1230.

Mishra AR and Rani P 2018 Interval-valued intuitionistic fuzzy WASPAS method: Application in reservoir flood control management policy. Gro. Dec. Nego. 27(6): 1047-1078.

Petrović G, Mihajlović J, Ćojbasić Ž, Madić M and Marinković D 2019 Comparison of three fuzzy MCDM methods for solving the supplier selection problem. Facta 
Universitatis Series: Mech. Eng. 17(3): 455-469.

Puertas R, Marti L and Garcia-Alvarez-Coque JM 2020 Food supply without risk: multicriteria analysis of institutional conditions of exporters. Int. J. Environ. Res. Pub. Health 17(10): 3432.

Rodcha R, Tripathi KN and Prasad SR 2019 Comparison of cash crop suitability assessment using parametric, AHP, and FAHP methods. Land 8(5): 79.

Rouyendegh BD and Erkan TE 2012 Selection of academic staff using the fuzzy analytic hierarchy process (FAHP): A pilot study. Technicki Vjesnik 19(4): 923-929.

Sabaei D, Erkoyuncu J and Roy R 2015 A review of multi-criteria decision-making methods for enhanced maintenance delivery. Procedia CIRP 37: 30-35.

Setyawan A, Arini FY and Akhlis I 2017 Comparative analysis of simple additive weighting method and weighted product method to new employee recruitment decision support system(DSS) at PT. Warta Media Nusantara. Sci. J. Inform. 4(1): 34-42.

Singh A and Malik SK 2014 Major MCDM techniques and their application-A review. IOSR J. Eng. 4(5): 15-25.

Srisawat C and Payakpate J 2016 Comparison of MCDM methods for intercrop selection in rubber plantations J. Inform. Comm. Technol. 15(1): 165-182.
Stojić G, Stević Ž, Antuchevičiene J, Pamučar D and Vasiljević M 2018 A novel rough WASPAS approach for supplier selection in company manufacturing PVC carpentry products. $J$. Inform. 9(5): 121.

Tesic D, Bozanic D and Jankovic D 2018 The use of the WASPAS method and fuzzy theory for assessing the flood hazard IV Int. Scie. Conf. Safety and Crisis MngtTheory and Practice: 130-138.

Turskis Z, Goranin N, Nurusheva A and Boranbayev S 2019 A fuzzy WASPASbased approach to determine critical information infrastructures of EU sustainable development. Sustainability 11(2): 424.

Turskis Z, Zavadskas EK, Antucheviciene J and Kosareva N 2015 A hybrid model based on fuzzy AHP and fuzzy WASPAS for construction site selection. Int. J. Comput. Commun. Control 10(6): 113128.

Wilkinson J and Rocha R 2009 Agro-industry trends, patterns and development impacts. Agro-industries for Development, Wallingford, UK: CABI for FAO and UNIDO: 46-91.

Xiong L, Zhong S, Liu S, Zhang, X and Li, Y 2020 An approach for resilient-green supplier selection based on WASPAS, BWM, and TOPSIS under intuitionistic fuzzy sets. Mathematical Problems in Engineering 2020. 